\title{
Review
}

Svitlana Strunina*, Jiri Hozman and Petr Ostadal

\section{The peripheral cannulas in extracorporeal life support}

https://doi.org/10.1515/bmt-2017-0107

Received June 28, 2017; accepted March 12, 2018; online first April 12,2018

\begin{abstract}
Femoral cannulation is a minimally invasive method which is an alternative method for central cannulation. This review focuses on the parameters and features of the available peripheral cannulas. Nowadays there exist many peripheral cannulas in a variety of sizes, configurations and lengths to meet the specific needs of the patients. Modern cannulas are strong, thin-walled and one piece reinforced constructions. Furthermore, modern cannulas are manufactured from a biocompatible material and surface coatings are applied to the cannulas to reduce the activation of the clotting. When peripheral cannulas are applied, bleeding, thrombosis and hemolysis are the most common complications.
\end{abstract}

Keywords: cannula dimensions; cannula material; cannula position; complications; extracorporeal membrane oxygenation; surface coating.

\section{Introduction}

Extracorporeal membrane oxygenation (ECMO) is a device that is used to support the failing lung and/or heart function. It is frequently used as a bridge to decision, ventricular assist device or for heart transplantation $[1,2]$. Likewise, successful use of ECMO has been reported in patients with circulatory collapse, due to acute cardiogenic shock, acute decompensation of congestive heart failure, drug intoxication, massive pulmonary embolism,

*Corresponding author: Svitlana Strunina, MSc, Faculty of Biomedical Engineering, Czech Technical University in Prague, Nám. Sítná 3105, 27201 Kladno, Czech Republic, Phone: +420 224359 714, Fax: +420 224358 419, E-mail: svitlana.strunina@fbmi.cvut.cz. https://orcid.org/0000-0001-9787-086X

Jiri Hozman: Faculty of Biomedical Engineering, Czech Technical University in Prague, Nám. Sítná 3105, 27201 Kladno, Czech Republic. https://orcid.org/0000-0003-4273-5235

Petr Ostadal: Cardiovascular Center, Na Homolce Hospital, Roentgenova 2/37, 15030 Prague, Czech Republic acute respiratory distress syndrome, accidental hypothermia and cardiopulmonary resuscitation [3-5]. The principle of ECMO is to draw a portion of the body's blood outside of the body, oxygenate it and then return it into circulation $[6,7]$. There are two types of ECMO. Extracorporeal membrane oxygenation in veno-arterial configuration (VA-ECMO) provides right atrium-to-aortic circulatory support [8] and is commonly used for patients with various etiologies of cardiogenic shock [9]. Extracorporeal membrane oxygenation in veno-venous configuration (VV-ECMO) provides right atrium-to-inferior vena cava circulatory support [8] and is commonly used for patients with respiratory failure [9].

Cannulas are used to provide the interface between the patient and the extracorporeal circuit. The peripheral ECMO cannulas are used for peripheral vessel cannulation. The main advantage of peripheral cannulation is that it does not require entering the chest for initiation of ECMO [9].

This review focuses on the available types and general properties of peripheral cannulas. The main tendencies of the currently used peripheral cannulas are discussed in this review. Complications relating to the peripheral cannulas during the ECMO are also presented.

\section{Types of peripheral cannula}

The peripheral ECMO cannulas provide greater versatility for cannulation techniques and strive for smaller incisions.

\section{Single-lumen peripheral cannulas}

Single-lumen peripheral cannulas are used to provide venous and arterial access for VA-ECMO or multiple site venous access for VV-ECMO [10-13].

The deoxygenated blood is drained through an inflow cannula. The oxygenated blood is returned via an outflow cannula [14] (Figure 1). 


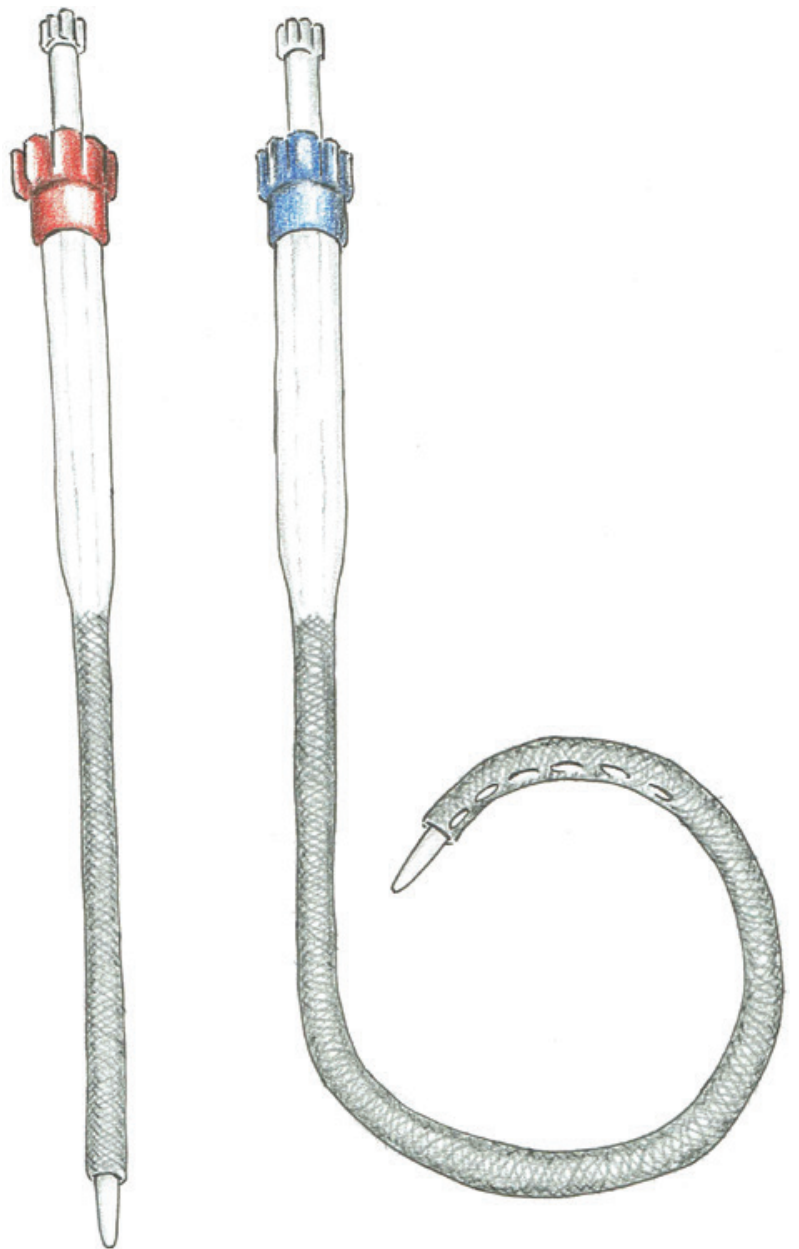

Figure 1: A peripheral outflow cannula (on the left) and a peripheral inflow cannula (on the right).

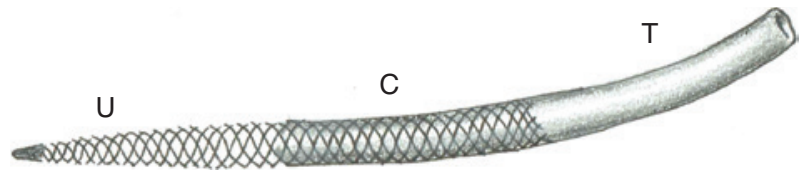

Figure 2: Smartcanula.

$\mathrm{T}$ - tubing, C - covered, $\mathrm{U}$ - uncovered.

Basically, a single-lumen peripheral cannula is an elastic tube with an orifice at the tip [10,15] and side holes. It has been shown that the side holes decrease the mechanical stress on blood components [16].

The alternative type of a single-lumen peripheral cannula is a Smartcanula (Smartcanula ${ }^{\circledR}$, Smartcanula LLC, Lausanne, Switzerland) (Figure 2). Its wire structure of the virtually wall-less device contrasts with the current design of the percutaneous cannulas. There is a virtually wall-less cannula with the open wall (mesh structure) which allows collapsed insertion and expansion in situ $[15,17]$. The design of Smartcanula allows decreasing the pressure drop throughout the cannula, thereby increasing the extracorporeal blood flow.

\section{Double-lumen peripheral cannulas}

Double-lumen cannulas combine both drainage and reinfusion lumens into one cannula [16] (Figure 3). This type of cannula is less invasive and provides venovenous support via a single jugular venous access site [10]. The right jugular vein cannulation has a much shorter route to the right atrium than the femoral cannulation. It can accommodate a much larger cannula for higher performance [18]. Using this type of cannula reduces the circuit size, which minimizes blood cells

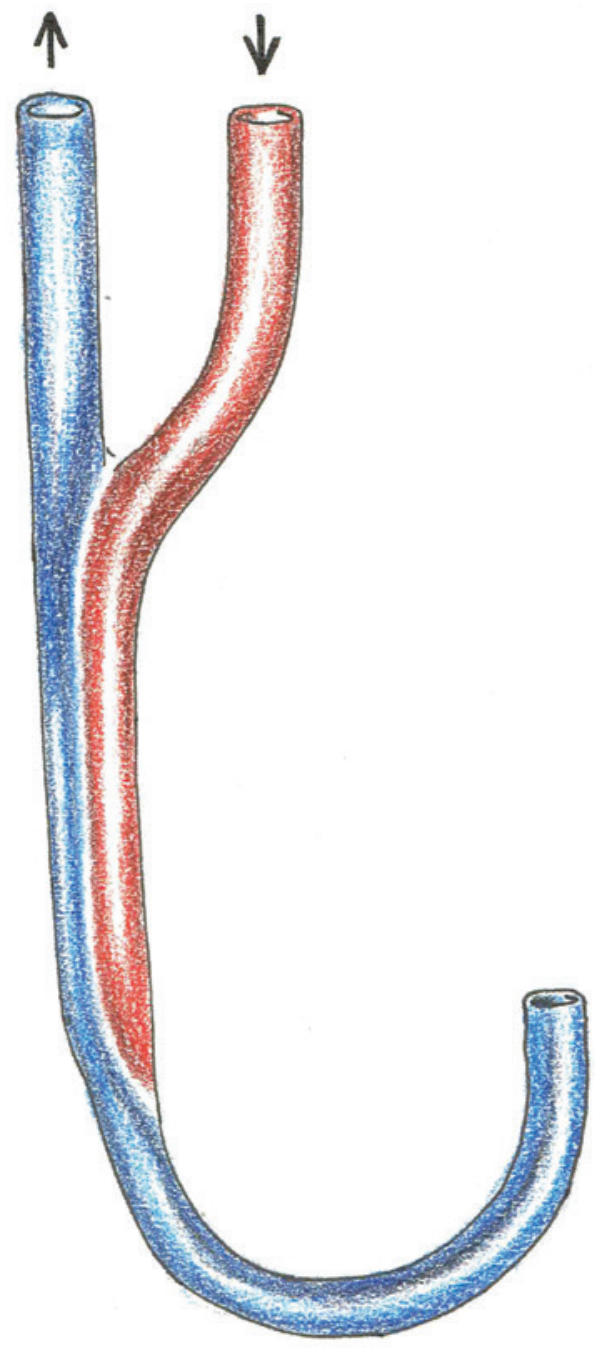

Figure 3: A double-lumen cannula. 
and circuit interaction. Nevertheless, the cannula size is much larger than that of the standard peripheral cannula and it is not very elastic which complicates its admission $[18,19]$. If the fluoroscopy is not available, the insertion of the double-lumen cannula is not recommended, because of the risk of right ventricular perforation [19].

\section{Cannulas' position}

In the veno-arterial configuration of ECMO, an inflow peripheral cannula is inserted via the femoral vein or via the right internal jugular vein with its tip in the right atrium. The outflow cannula is inserted via the femoral artery with the tip position in the iliac artery or in the distal abdominal aorta. Another approach of an inflow peripheral cannula insertion is via the subclavian artery with the tip position into the ascending aorta $[3,5,6,9$, 20-22].

In the veno-venous configuration of ECMO, the peripheral cannulas are usually introduced via the femoral and jugular veins with the cannula tips at the border between the right atrium and the superior and inferior caval veins to minimize recirculation [23]. In the case of using a double-lumen cannula, the right-sided jugular vein is used for insertion $[9,22,24,25]$.

\section{Material}

Modern cannulas are strong, one-piece polyurethane molding construction. The cannulas are manufactured from biocompatible silicone polyurethane polymer, which may be coated with polymers that may reduce platelet activation and the inflammatory response at the blood-cannula interface. Cannulas combine flexibility and resistance, e.g. polyurethane has high material strength at room temperature and becomes more malleable at body temperature (this aids the insertion of the cannula) [10, 16, 21].

The cannulas are constructed with a reinforced stainless steel (SS) wire. Wire reinforcement of the cannula walls is used to prevent kinking or collapse $[10,16,26]$. This type of design provides longer-term ambulatory application [18]. The cannulas that were manufactured from non-wire-reinforced polyurethane were deformed after insertion. Kinking and collapse of the cannula caused by excessive suction can result in a disastrous interruption of ECMO flow [10].
A rigid cannula introducer is made of polyvinylchloride with an embedded SS rod [18].

\section{Surface coating}

Nevertheless, modern cannulas are made of biocompatible materials and surface coatings are applied on the cannula to reduce the activation of the clotting; control of blood clotting is mandatory during the extracorporeal life support (ECLS) [16, 21].

Currently, the trends are to prevent blood clotting without using anticoagulants [27]. Heparin-coated surfaces result in reduced complement and inflammatory activation due to its anti-inflammatory properties. Nevertheless, heparin causes the development of osteopenia and thrombocytopenia [16, 28]. Heparin-coated surfaces can release cytokines, which exert a damaging effect on the lungs [29]. Furthermore, heparin-based coatings can leach into the blood and result in the exposure of the blood to extremely high heparin doses (>50 U/kg) [30]. This can cause excessive bleeding and can be lethal.

Nowadays biocompatible surfaces more closely resemble the physiological endothelium. The coatings have a hydrophilic outer layer and some contain negatively charged groups to repel negatively charged proteins and platelets and thereby create a layer between the components of human blood and the artificial surface. For example, "Balance Biosurface" by Medtronic and "X Coating” by Terumo [16].

An alternative coating material for ECLS cannulas is bivalirudin (BVLD). BVLD is a short, synthetic peptide, derived from hirudin, that is potent, highly specific and a reversible thrombin inhibitor which is used as a surface coating. It was reported that BVLD was covalently conjugated on plasma polymerized allylamine (PPAam) coated 316L SS to develop an anticoagulant surface. The BVLD-PPAam-modified 316L SS disk was implanted in the femoral artery of dogs for 5 weeks. The anticoagulant surface prevented thrombosis formation by rapidly growing a homogeneous and intact endothelium on its surface $[16,28]$.

The next nonheparin coating is tethered-liquid perfluorocarbon (TLP). The TLP resisted adhesion of fibrin and platelets, suppressed biofouling and reduced thrombosis and bacterial adhesion. Medical materials with a TLP coating have antithrombogenic and antibiofouling surfaces that do not require co-administration of antiplatelet, anticoagulant or antibiotic medications. It was reported that the TLP-coated tubing and catheters in large blood vessels in pigs retained their ability to prevent 
occlusive thrombus formation for $8 \mathrm{~h}$ without the use of blood thinners such as heparin $[27,30]$.

\section{Dimensions}

The size and location of the inflow and outflow cannulas impact tissue oxygenation as well as the degree of cardiac support provided. The intent of appropriate cannula choice is to provide full flow without damaging the cells, particularly erythrocytes, from excessive shear stress and turbulence [9]. The currently used peripheral ECLS cannulas for adults typically range from 18 to $29 \mathrm{Fr}$ for venous and 13-23 Fr for arterial cannulas [9, 21, 31]. The doublelumen cannula sizes for adults are from 13 to $31 \mathrm{Fr}$ for Avalon Elite Bi-Caval Dual Lumen Catheters [32] and from 13 to $32 \mathrm{Fr}$ for OriGen dual lumen catheters [33].

For adult patients, the cannula length is variable and may range from $50 \mathrm{~cm}$ for inflow and from $18 \mathrm{~cm}$ for outflow cannulas depending upon the manufacturer, the anatomy of the patient and the vasculature [21]. The insertion length of peripheral cannulas for adults may vary in range from 38 to $55 \mathrm{~cm}$ for inflow and from 15 to $23 \mathrm{~cm}$ for outflow cannulas [31]. For double-lumen cannulas, Avalon Elite Bi-Caval Dual Lumen Catheters, the insertable length range is from $11 \mathrm{~cm}$ to $31 \mathrm{~cm}$ [32]. The insertable length of OriGen dual lumen catheters is from $8 \mathrm{~cm}$ to $25 \mathrm{~cm}$ [33].

By minimizing the cannula thickness, the internal diameter increases thereby obtaining the highest flow efficiency and cannula flexibility with the smallest anatomical footprint $[8,18]$. Nowadays, the ultrathin wall of percutaneous cannula achieves a thickness of $0.48 \mathrm{~mm}$ for adult cannulas and $0.38 \mathrm{~mm}$ for pediatric cannulas [34]. Doublelumen cannula for VV-ECMO has a wall thickness of $0.7 \mathrm{~mm}$ with a thin membrane sleeve of the infusion lumen inside the main body with a wall thickness of $0.3 \mathrm{~mm}$ [18].

There are a lot of opinions regarding recommending the cannula size. The size of the cannula is recommended depending on the patient's anatomic features and the weight or body surface area (BSA) [14, 21, 35]. Depending on the patient's anthropological parameters, the cannula should reach from the peripheral insertion point to a central location. Some data suggest that the cannula size should be determined in relation to the actual size of the vessel $[10,16,21,35]$.

Nevertheless, because many different cannulas exist, studying the flow chart of each cannula is commonly used to determine the appropriate size [36]. The cannula provides a resistance within the ECMO circuit and, therefore, creates a pressure drop (the difference between the pressure entering the cannula and that of leaving) across it [24]. The pressure-flow characteristics of cannulas are dependent on their length and internal diameter [37].

Pressure drop versus flow charts of the outflow and inflow cannulas from the manufacturers is based on the evaluations using water as the testing solution [38] at an ambient temperature. The blood flow in the circuit during ECMO may vary depending on blood viscosity, the patient's anatomy and circuit configuration.

With a higher pressure across the cannula, there is an increase in jetting at the tip, that can cause intimal damage to the vessel [24]. The high pressure flow becomes turbulent [16] and may damage the red blood cells. In addition, it can be the cause of microbubbles [39] and induce bubble emboli.

The accepted limit of pressure drop is $100 \mathrm{~mm} \mathrm{Hg}$. This should not ordinarily be exceeded [24].

Therefore, the largest possible cannula can be recommended to maximize blood flow. Nonetheless, small cannulas provide support by reducing bleeding complications [40], the risk of vascular damage, ischemia and obstruction of arteries [39].

\section{Complications}

ECMO is an effective circulatory support technology. Nevertheless, this method has a number of complications $[8,22,41]$. The most common complications of currently used peripheral cannulas are bleeding, thrombosis and hemolysis.

\section{Bleeding}

Bleeding is the most frequent complication for patients receiving ECMO therapy [3, 39]. Brunner et al. [3] reported a meta-analysis, in which 20 studies were analyzed including 1866 patients in whom bleeding was estimated at a rate of $41 \%$. The most frequent source of hemorrhage is the femoral cannula insertion site. Currently, the most commonly used antithrombotic therapy is systemic anticoagulation with unfractionated heparin, which is associated with its well-known complications including bleeding (patient) and clotting (circuit) [3, 39]. Systemic anticoagulation complications in ECMO support have not really reduced despite developments in technology and monitoring methods [3]. 


\section{Ischemia}

Vascular issues are the second most frequent complication of using cannulas. Local complications can occur particularly at the site of the peripheral insertion of ECMO. The most concerning is the lower extremity ischemia [3, 9, 39], which is induced by obstruction of the femoral artery by the outflow cannula during VA-ECMO, which occurs in $10-20 \%$ of the patients [39]. For this reason, some centers attempt to restore the cannulated limb perfusion after noting the absence of anterior and posterior tibial artery flow. The flow is restored by inserting a 5-10 Fr percutaneous reperfusion catheter distally to the arterial cannula (Figure 4) by means of a vascular ultrasound scan as soon as possible after ECMO implantation. The reperfusion catheter is joined by a short tube to the side port of the cannula and it enables the individual perfusion of the lower limb [3, 5, 9, 24, 37, 39].

Matsui et al. [5] reported a cannula, which has a simple structure with two small holes with a diameter of $2 \mathrm{~mm}$ in the side wall at the distance of 103 and $110 \mathrm{~mm}$

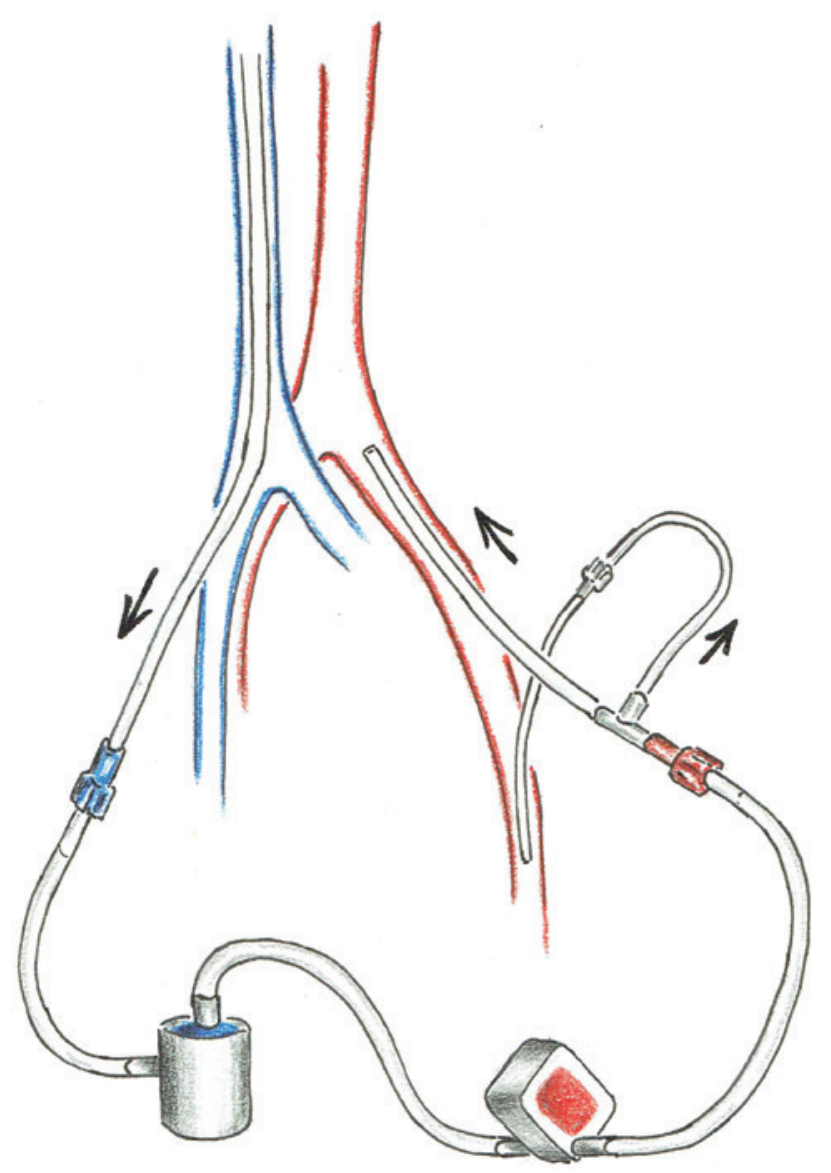

Figure 4: Limb perfusion by a catheter inserted distally into the arterial cannula during VA-ECMO.

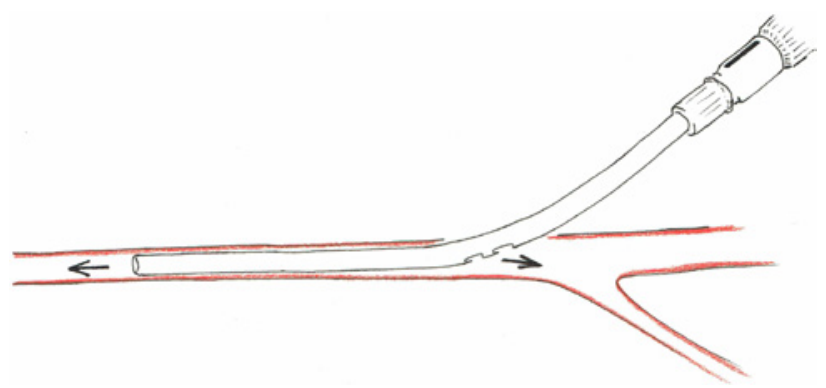

Figure 5: A peripheral cannula with holes for limb reperfusion.

from the tip of the cannula, which could provide the distal limb with blood flow without specialized techniques (Figure 5). There is a marking line on the opposite side of the two side holes [5].

\section{Hemolysis}

Hemolysis during ECMO therapy remains a concern with a reported incidence between 5 and 18\%. The major contributors are technical-induced hemolysis that may consist of sub lethal damage to erythrocytes by shear stress, high ECMO blood flow in the instance of high flow velocity through small cannulas, cavitation in the instance of hypovolemia and pressure changes within the oxygenator thrombosis upon the membrane. Consequently, renal insufficiency or multiple organ failure can appear [3].

\section{Conclusion}

This paper reviewed the main parameters of peripheral cannulas and problems relating to the peripheral cannulas for the ECMO therapy. Today's peripheral cannula has one-piece, biocompatible, thin-walled, kink resistant, wire-wound bodies. Construction of the cannula maximizes flow rates and flexibility. Reported information can help to determine trade-offs or help managers to plan to reduce the risk of failure and injury and improve the efficiency of ECLS therapy.

Acknowledgment: The authors thank Eva Motyčková from Faculty of Biomedical Engineering, Czech Technical University in Prague for help and support.

\section{Author Statement}

Research funding: Authors state no funding involved. Conflict of interest: Authors state no conflict of interest. 
Informed consent: Informed consent is not applicable. Ethical approval: The conducted research is not related to either human or animals use.

\section{References}

[1] Li S, Yang W, Chuang C. Effect of early and intensive continuous venovenous hemofiltration on patients with cardiogenic shock and acute kidney injury after cardiac surgery. J Thorac Cardiovasc Surg 2014;148:1628-33.

[2] Pappalardo F, Montisci A. Veno-arterial extracorporeal membrane oxygenation (VA ECMO) in postcardiotomy cardiogenic shock: how much pump flow is enough? J Thorac Dis 2016;8:E1444-8.

[3] Brunner M, Banfi C, Giraud R. Venoarterial Extracorporeal Membrane Oxygenation in Refractory Cardiogenic Shock and Cardiac Arrest. Extracorporeal Membrane Oxygenation - Advances in Therapy. Rijeka: InTech; 2016. Ch. 6.

[4] Massetti M, Gaudino M, Crea F. How to transform peripheral extracorporeal membrane oxygenation in the simplest mid-term paracorporeal ventricular assist device. Int J Cardiol 2013;166:551-3.

[5] Matsui Y, Shimura S, Suto Y, Fukase S, Tanaka A, Sasaki S. A novel femoral arterial cannula to prevent limb ischemia during cardiopulmonary support: preliminary report of experimental and clinical experiences. Artif Organs 2006;30:557-60.

[6] Hochman JS, Ohman EM. Cardiogenic Shock. Hoboken, NJ, USA: Wiley; 2009:200-19.

[7] Zhang Z, Song T, Yang Y, Meng G, Zhao J, Wang C, et al. Combining ECMO with IABP for the treatment of critically Ill adult heart failure patients. Heart Lung Circ 2013;23:363-8.

[8] Jegger D, Corno AF, Mucciolo A, Mucciolo G, Boone Y, Horisberger J, et al. A prototype paediatric venous cannula with shape change in situ. Perfusion 2003;18:61-5.

[9] Jayaraman A, Cormican D, Shah P, Ramakrishna H. Cannulation strategies in adult veno-arterial and veno-venous extracorporeal membrane oxygenation: techniques, limitations, and special considerations. Ann Card Anaesth 2017;20:11-8.

[10] Lequier L, Horton SB, McMullan DM, Bartlett RH. Extracorporeal membrane oxygenation circuitry. Pediatr Crit Care Med 2013-6;14(5 Suppl 1):S7-12.

[11] Léger P, Guilbert J, Isambert S, Le Saché N, Hallalel F, Amblard $A$, et al. Pediatric single-lumen cannula venovenous extracorporeal membrane oxygenation: a French center experience. Artif Organs 2013;37:57-65.

[12] Medtronic. Adult Extracorporeal Circuit Cannulae [online]. 2016. [cited 2017 February 15]. Available from: http://www. medtronic.com/us-en/healthcare-professionals/products/cardiovascular/cannulae/adult-extracorporeal-circuit.html.

[13] Schmidt F, Kuebler J, Ganter M, Jack T, Meschenmoser L, Sasse $M$, et al. Minimal invasive lung support via umbilical vein with a double-lumen cannula in a neonatal lamb model: a proof of principle. Pediatr Surg Int 2016;32:75-82.

[14] Bonacchi M, Harmelin G, Peris A, Sani G. A novel strategy to improve systemic oxygenation in venovenous extracorporeal membrane oxygenation: the " $\chi$-configuration". J Thorac Cardiovasc Surg 2011;142:1197-204.
[15] Abdel-Sayed S, Favre J, von Segesser LK. How to prevent venous cannula orifice obstruction during extracorporeal circulation. Perfusion 2015;30:187-94.

[16] Kohler K, Valchanov K, Nias G, Vuylsteke A. ECMO cannula review. Perfusion 2013;28:114-24.

[17] Berdajs D, Ferrari E, Michalis A, Burki M, Pieterse CW, Horisberger J, et al. New prototype of femoral arterial SmartCannula with anterograde and retrograde flow. Perfusion 2011;26:271-5.

[18] Condemi F, Wang D, Fragomeni G, Yang F, Zhao G, Jones C, et al. Percutaneous double lumen cannula for right ventricle assist device system: a computational fluid dynamics study. Biocybern Biomed Eng 2016;36:482-90.

[19] Ko M, dos Santos PR, Machuca TN, Marseu K, Waddell TK, Keshavjee S, et al. Use of single-cannula venous-venous extracorporeal life support in the management of life-threatening airway obstruction. Ann Thorac Surg 2015;99:e65.

[20] Douflé G, Roscoe A, Billia F, Fan E. Echocardiography for adult patients supported with extracorporeal membrane oxygenation. Crit Care 2015;19:1-10.

[21] Beckmann A, Benk C, Beyersdorf F, Haimerl G, Merkle F, Mestres $C$, et al. Position article for the use of extracorporeal life support in adult patients. Eur J Cardiothorac Surg 2011;40:676-80.

[22] Madershahian N, Nagib R, Wippermann J, Strauch J, Wahlers T. A simple technique of distal limb perfusion during prolonged femoro-femoral cannulation. J Card Surg 2006;21:168-9.

[23] Napp LC, Kühn C, Hoeper MM, Vogel-Claussen J, Haverich A, Schäfer A, et al. Cannulation strategies for percutaneous extracorporeal membrane oxygenation in adults. Clin Res Cardiol 2016;105:283-96.

[24] Lich B, Brown D. The Manual of Clinical Perfusion (Second Edition Update). 2nd ed. Fort Myers, FL: Perfusion.com; 2004.

[25] Napp LC, Bauersachs J. Triple Cannulation ECMO. Extracorporeal Membrane Oxygenation - advances in Therapy. Rijeka: InTech; 2016. Ch. 5.

[26] Medtronic. Select 3D ${ }^{\circledR}$ EOPA 3D ${ }^{\circledR}$ Arterial Cannulae [online]. 2012. [cited 2016 December 9]. Available from: http://pdf. medicalexpo.com/pdf/medtronic/select-3d-eopa-3d-arterialcannulae/70691-134576.html.

[27] Wyss Institute. Bioinspired Coating for Medical Devices Repels Blood and Bacteria [online]. 2014. [cited 2017 March 11]. Available from: https://wyss.harvard.edu/bioinspired-coatingfor-medical-devices-repels-blood-and-bacteria/.

[28] Yang Z, Tu Q, Maitz MF, Zhou S, Wang J, Huang N. Direct thrombin inhibitor-bivalirudin functionalized plasma polymerized allylamine coating for improved biocompatibility of vascular devices. Biomaterials 2012;33:7959-71.

[29] Saito N, Motoyama S, Sawamoto J. Effects of new polymercoated extracorporeal circuits on biocompatibility during cardiopulmonary bypass. Artif Organs 2000;24:547-54.

[30] Leslie DC, Ingber DE, Waterhouse A, Berthet JB, Valentin TM, Watters AL, et al. A bioinspired omniphobic surface coating on medical devices prevents thrombosis and biofouling. Nat Biotechnol 2014;32:1134-40.

[31] Maquet. HLS Cannulae [online]. 2015. [cited 2017 January 27]. Available from: https://www.maquet.com/globalassets/ downloads/products/hls-cannulae-set/hlscannulae_mcp_ br_10018_en_1_screen.pdf?lang=en\&src=/int/products/hlscannulae-set/?ccid=24. 
[32] Maquet. Avalon Elite ${ }^{\circledR} \mathrm{Bi}$-Caval Dual Lumen Catheter [online]. 2015. [cited 2017 January 20]. Available from: https://www. maquet.com/globalassets/downloads/products/avalon-elite/ avalonelite_mcp_br_10012_en_1_screen.pdf?lang=en\&src=/ int/products/avalon-elite/.

[33] OriGen. Reinforced Dual Lumen Catheters. http://www.origen. com 2017 Catalog.

[34] Medtronic. Cannula Catalog 2017 [online]. 2017. [cited 2018 March 23]. Available from: http://www.medtronic.com/mics/ documents/2017-Medtronic-Cannula-Catalog.pdf.

[35] Grasselli G, Pesenti A, Marcolin R, Patroniti N, Isgro S, Tagliabue $P$, et al. Percutaneous vascular cannulation for extracorporeal life support (ECLS): a modified technique. Int J Artif Organs 2010;33:553-7.

[36] Menon PG, Antaki JF, Undar A, Pekkan K. Aortic outflow cannula tip design and orientation impacts cerebral perfusion during pediatric cardiopulmonary bypass procedures. Ann Biomed Eng 2013;41:2588-602.
[37] Foley DS, Swaniker F, Pranikoff T, Bartlett RH, Hirschl RB. Percutaneous cannulation for pediatric venovenous extracorporeal life support. J Pediatr Surg 2000;35: 943-7.

[38] Qiu F, Clark JB, Kunselman AR, Ündar A, Myers JL. Hemodynamic evaluation of arterial and venous cannulae performance in a simulated neonatal extracorporeal life support circuit. Perfusion 2011;26:276-83.

[39] Petr O, Bělohlávek J. ECMO: extrakorporální membránová oxygenace: manuál pro použití u dospělých. Praha: Maxdorf; 2013.

[40] Takayama H, Landes E, Truby L, Fujita K, Kirtane AJ, Mongero $\mathrm{L}$, et al. Feasibility of smaller arterial cannulas in venoarterial extracorporeal membrane oxygenation. J Thorac Cardiovasc Surg 2015;149:1428-33.

[41] Foley PJ, Morris RJ, Woo EY, Acker MA, Wang GJ, Fairman RM, et al. Limb ischemia during femoral cannulation for cardiopulmonary support. J Vasc Surg 2010;52:850-3. 